\title{
A data acquisition system for the remote measurement of flow in open channels
}

\author{
J. Martínez \\ Mexican Institute of Water Technology (IMTA), Mexico
}

\begin{abstract}
At present, water is increasingly scarce, so a constant infrastructure for the operation and distribution of the resource is required, however, the control of spending on water resources using measurements performed by different types of electrical, electromechanical and ultrasonic meters is also required.

The objective of this study was to create a wireless data acquisition system that is accurate, friendly and much cheaper than the afore-mentioned relationship, with the possibility for its application to dams, canals and rivers, for the elimination of human error in its operation and the removal of any maintenance required from abroad.

In order to achieve this, better measurement systems are required. This paper presents a data acquisition system and economic dynamic that allows the gauging of measurements wirelessly, processing the captured parameters that are needed to calculate a gauging, as well as the pulses that give us the velocity meter model price, and later get the speed and real time spending with the ability to store or print information.
\end{abstract}

Keywords: mechanical flow meters, testing laboratory, LabVIEW based automation system.

\section{Introduction}

- Water is now an important factor for mankind. Measuring the supply to all sectors continues to be less important, especially with a constantly growing population. A program of infrastructure development across the country, as well as a statistical measurement of supply, is required. 
- The measurements were carried out using different types of instruments and were also made abroad, using sophisticated technology, and we depend on them for any repairs or maintenance work.

- This paper presents the design of a measurement gauging tool (which gives the measurement of the expenditure or water flow that leads to the canal or river). It is an intelligent system that will process the information it receives, providing real-time spending. The system is economical, precise and dynamic.

- Considering the data acquisition system proposed here, the following topics need to be discussed: the different types of cross-sectional areas of the measurement points, the selection of the type of measuring instrument, determination of the frequency of transmission and communication equipment and the data acquisition technique.

\section{Development}

The following development aspects were considered: a review of cross-sectional areas [4], which found rectangular area types with side contractions, trapezoidal and heterogeneously. In all except the rectangular type, it is necessary to apply equation (1) in order to determine the average of each strap section.

$$
\mathrm{D}=(\mathrm{A}+2 \mathrm{~B}+\mathrm{C}) / 4
$$

$\mathrm{D}=$ average strap

$\mathrm{A}=$ initial brace (end)

$\mathrm{B}=$ central bolt

$\mathrm{C}=$ tight end (end)

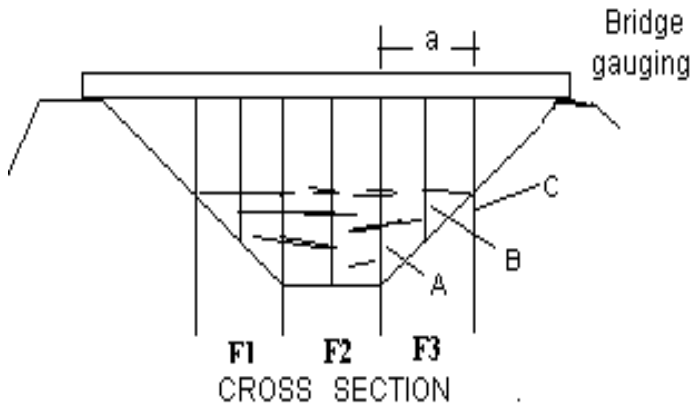

Figure 1: Trapezoidal area.

Calculate the area of the strip (A) as the product of the strap means (D) and the strip width (a) applies equation (2):

$$
\mathrm{A}=\mathrm{a}+\mathrm{D}
$$

To calculate the cross-sectional area applying equation (3), (At) adding the area of the strips (W):

$$
\mathrm{At}=\mathrm{A} 1+\mathrm{A} 2+\mathrm{A} 3+--\mathrm{An}
$$


If the bottom of the river looks like a parabola the area can be estimated using equation (4):

$$
A t=2 / 3(a+y)
$$

$$
\begin{aligned}
\text { At } & =\text { cross sectional area }(\mathrm{m} 2) \\
\mathrm{a} & =\text { width mirror of water }(\mathrm{m}) \\
\mathrm{y} & =\text { depth }(\mathrm{m})
\end{aligned}
$$

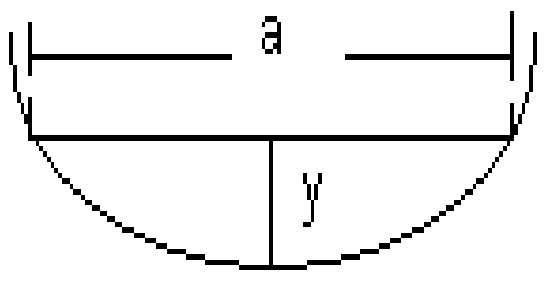

Figure 2: Area parabolic type.

The following is a description of the system developed, which is composed of several stages.

Interface, input interface and the reception pulse-rate meter with the transmitter are shown in Figure 3.

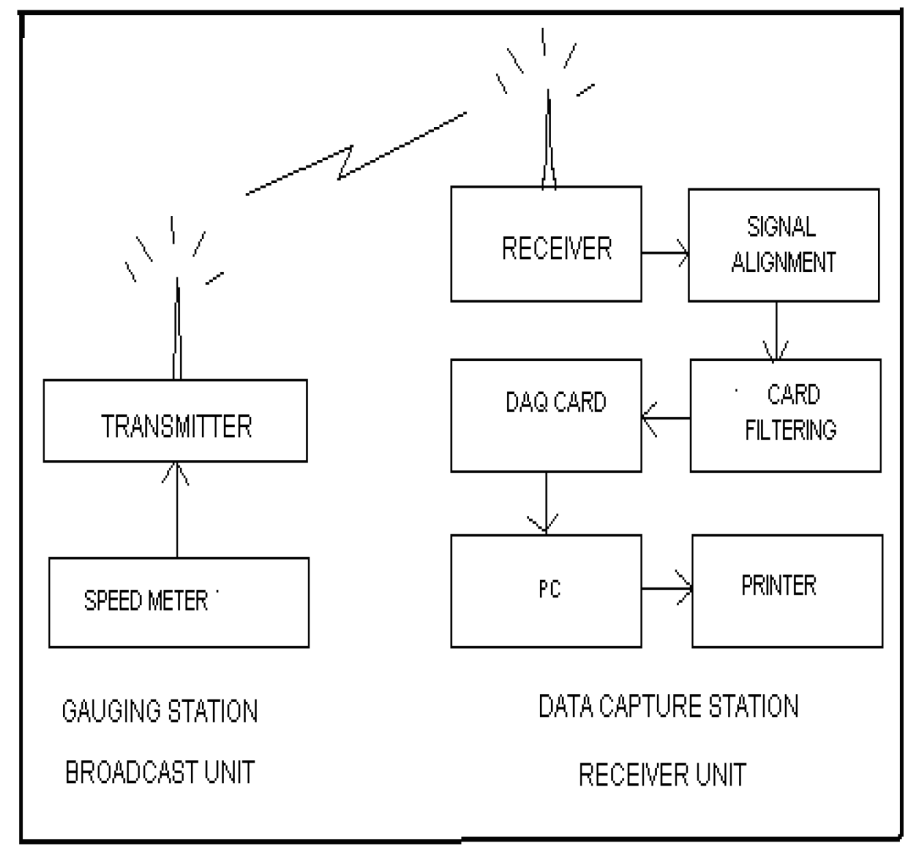

Figure 3: Block diagram of the DAQ system. 


\subsection{Computer (PC)}

The computer is responsible for implementing a program developed with National Instrument software called Labview, processing meter signals necessary to perform calculations of capacity.

\subsection{DAQ card}

This type of data acquisition is the sampling of the real world (analog system) to generate data that can be manipulated by a computer or other electronic media (digital). It involves taking a set of physical signals, converting them into electrical voltages and digitizing them, so that they can be processed in a computer.

The card features are as follows:

- PCI 6071;

- 16 to 64 Analog inputs;

- 8 Channels of $\mathrm{I} / \mathrm{O}$;

- Two 24 bits Timers, $20 \mathrm{MHz}$.

\subsection{Interface signal conditioning}

The signal conditioning interface is a conditioning step, which performs the adaptation of the signal to levels compatible with the element that makes the transformation to a digital signal.

\subsection{Receive interface}

The signal reception interface [1], is responsible for receiving the pulses and by means of a transducer converts an analog output signal and sends the signal to a data acquisition card.

\subsection{Receiver}

The receiver is responsible for receiving the RF signal from the transmitter, to provide a light signal that can be interpreted by the receiving interface.

\subsection{Speed meter and transmitter}

The flow meter [5] is described in Table 1, considering the cost, with increased demand in the market and with a range of acceptable speeds. Figure 4 shows an instrument used in rivers and canals to take the speed measurement, called a windlass, and regards to the electromechanical model, its rotation is performed through cones, these meters are calibrated and the characteristic equation is used in the developed program. 
Table 1: Comparison of flow meters.

\begin{tabular}{|c|c|c|c|c|c|}
\hline $\begin{array}{l}\text { Approximate } \\
\text { percentage of } \\
\text { population at } \\
\text { the national } \\
\text { equipment }\end{array}$ & Model & Advantage & Disadvantage & $\begin{array}{l}\text { Cost - } \\
\text { thousands } \\
\text { of dollars }\end{array}$ & $\begin{array}{l}\text { Range } \\
\text { speed } \\
\mathrm{m} / \mathrm{s}\end{array}$ \\
\hline 68.5 & $\begin{array}{l}\text { Electro } \\
\text { mechanical }\end{array}$ & $\begin{array}{l}\text { Practical, } \\
\text { sturdy error } \\
2 \%\end{array}$ & $\begin{array}{l}\text { Non-standard } \\
\text { parts }\end{array}$ & 0.8 & 0.02 a 4 \\
\hline 15 & $\begin{array}{l}\text { Electro } \\
\text { mechanical }\end{array}$ & $\begin{array}{l}\text { Practical, } \\
\text { sturdy error } \\
2 \% \\
\end{array}$ & $\begin{array}{l}\text { Non-standard } \\
\text { parts }\end{array}$ & 0.5 & 0.02 a 0.9 \\
\hline 3 & Horizontal & $\begin{array}{l}\text { Practical, } \\
\text { sturdy, } \\
\text { aerodynamic, } \\
\text { less flow } \\
\text { resistance, } \\
\text { error } 0.1 \%\end{array}$ & Not practical & 11 & 0.02 a 5 \\
\hline 2 & Horizontal & $\begin{array}{l}\text { Practical, } \\
\text { sturdy, } \\
\text { aerodynamic, } \\
\text { less flow } \\
\text { resistance, } \\
\text { error } 0.1 \%\end{array}$ & $\begin{array}{l}\text { Not very } \\
\text { practical }\end{array}$ & 0.8 & 0.02 a 2 \\
\hline 0.5 & Ultrasonic & $\begin{array}{l}\text { The answer is } \\
\text { not very direct, } \\
\text { accurate, error } \\
0.001 \%\end{array}$ & $\begin{array}{l}\text { High cost and } \\
\text { foregoing } \\
\text { technology }\end{array}$ & 85 & $\begin{array}{l}0.001 \mathrm{a} \\
4.5\end{array}$ \\
\hline 7 & Ultrasonic & $\begin{array}{l}\text { The answer is } \\
\text { not very direct, } \\
\text { accurate, error } \\
0.001 \%\end{array}$ & $\begin{array}{l}\text { High cost and } \\
\text { foregoing } \\
\text { technology }\end{array}$ & 288 & $\begin{array}{l}0.001 \mathrm{a} \\
15\end{array}$ \\
\hline
\end{tabular}

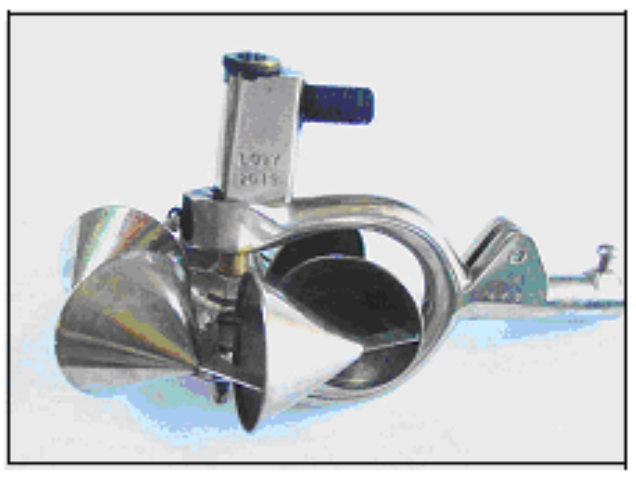

Figure 4: Flow meter as electromechanical model.

This meter is grouped with the transmitter so that the flow meter pulses are sent to the receiver. 


\subsection{Description of the software}

Figure 5 shows a flow chart of the measurement system, where we begin by asking for a key, should you exit the program incorrectly, and if correct then we go to the main menu where you can: measure a capacity, carry out some LV edits or exit the system.

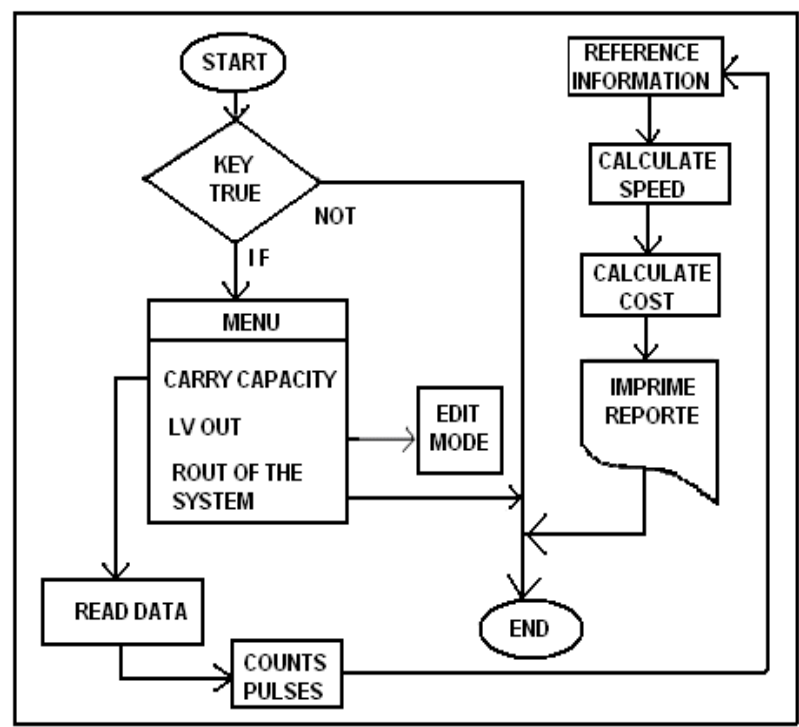

Figure 5: Flow diagram of the measurement system.

The Selecting Perform Capacity parameters are introduced, which are required to allow you to start the counting process that begins to store information, and to later make the necessary calculations with the information that was given previously. Thus ending the process and the results can be printed.

The software was developed in Labview version 9 of National Instrument and consists of three stages which are as follows.

\subsection{Capture parameters}

This stage presents an introduction screen and asks for an identification key, which if not entered correctly, has a 20 -second time out of the system. If the key is correct then a menu appears, where you can select any option; Perform a capacity, Labview or Exit to exit the system, if you select the first option you proceed to step two. 


\subsection{Capture meter speed information}

When performing the capture of information at each reading the values are changing pulse time and the value of $\mathrm{N}$, which is a relationship between times, revolutions, speed, the station width, area and number of reading or station.

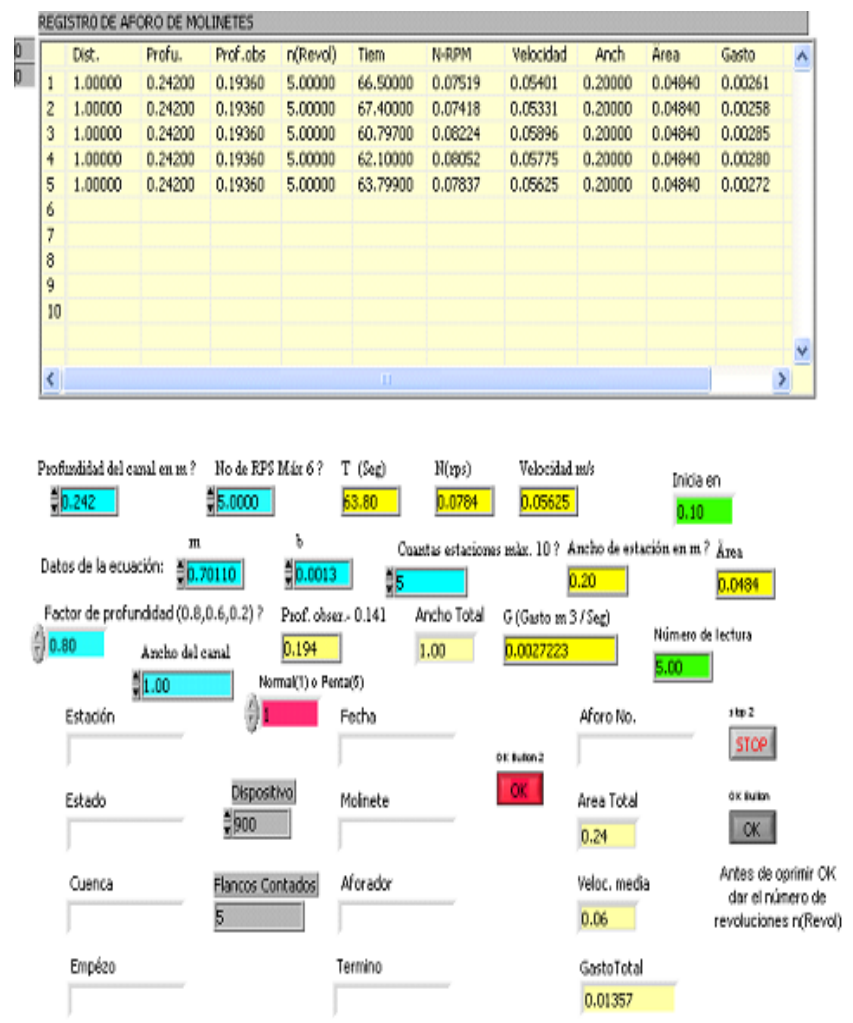

Figure 6: Results of a sheet capacity.

\subsection{Necessary calculations and results display}

Upon completion of reading the number or stations, the necessary calculations are performed and all the data from the results sheet, as shown in Figure 6, is displayed [2]: The total area, average speed and total expenditure.

The results are given to the ten thousandth, which is enough for gauging statistics.

The range in which the system operates covers the specifications for the flow meter, which was designed so that it should be 0.2 to $4.5 \mathrm{~m}$.

These meters are robust and well accepted by users, as shown in Table 1. To date, these meters have existed in the market for about 86 years and although there have been others with certain modifications, they retain the same principle, and perform the rotation using cones. 


\subsection{Store or print}

After processing the results, we may store or print the results. Note that the program has a multiplier, for when conducting appraisals with great speeds.

\section{Results}

The tests were able to detect and correct design errors throughout the stages of system development. We checked that the access steps and capture information remained at the correct time at the beginning and end of the process, in order to carry out calculations according to the data received in the receiving step to receive the input pulses until the data acquisition card.

The program controls how much of a break is given between each reading, anticipating a change in the process of capacity, as the depth values change.

\subsection{Performance tests}

The tests were performed to check the performed simultaneous operation of each of the elements of the system.

The testing of the data acquisition system was performed in a laboratory environment. Figure 7 shows a model of a dam and its output which is a straight channel, allowing for the flow velocity variations [3]. This was divided into stations with a width of $20 \mathrm{~cm}$, which placed the meter to $1 / 6$ deep.

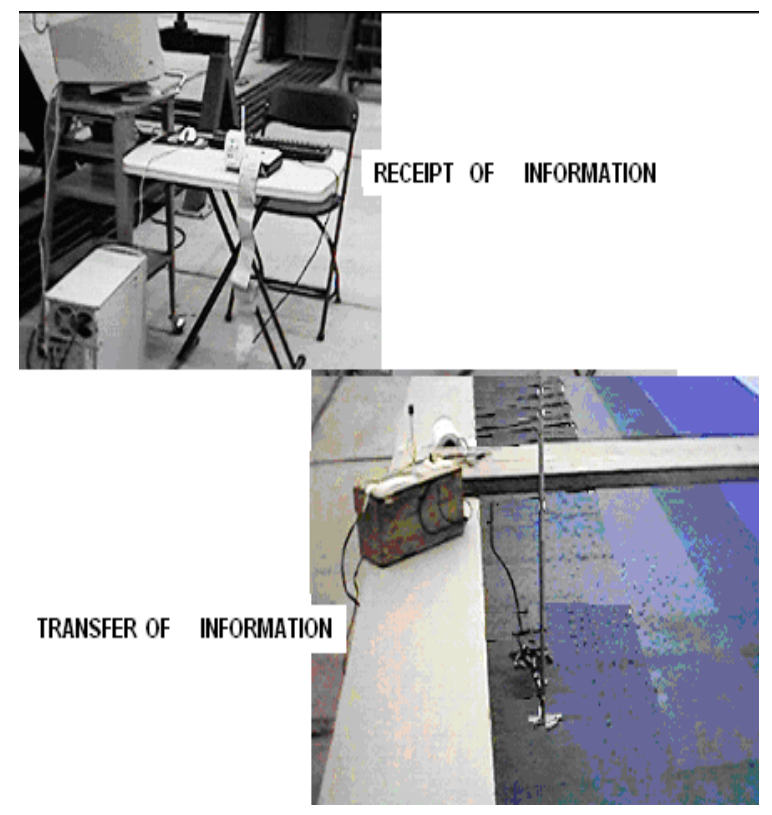

Figure 7: Laboratory tests. 
Measurements were carried out in three different ranges of flow velocity, the data is as follows:

$\mathrm{H}=\operatorname{strap}(0,052+0,049) / 2=0.05 \mathrm{~m}$

$$
\text { Data capacity } 1
$$

Opening of the valve 11/2 laps.

Data gauging 2

$\mathrm{H}=\operatorname{strap} 0092 \mathrm{~m}$

Opening of the valve 13/2 laps.

\section{Data gauging 3}

$\mathrm{H}=\operatorname{strap}=0128 \mathrm{~m}$

Opening of the valve $15 / 2$ laps.

Once having accumulated the results, as shown in Figure 8, for a comparison with what was obtained from the curve of elevations and capacities obtained [6] ISO-1438 "Open Channel Hidrometry-flow measurement using thin-plate weirs", these gauging results obtained are marked with red, and as it is shown they are very similar to those obtained in the curve.

\section{Curve elevations capabilities for thin plate weirs}

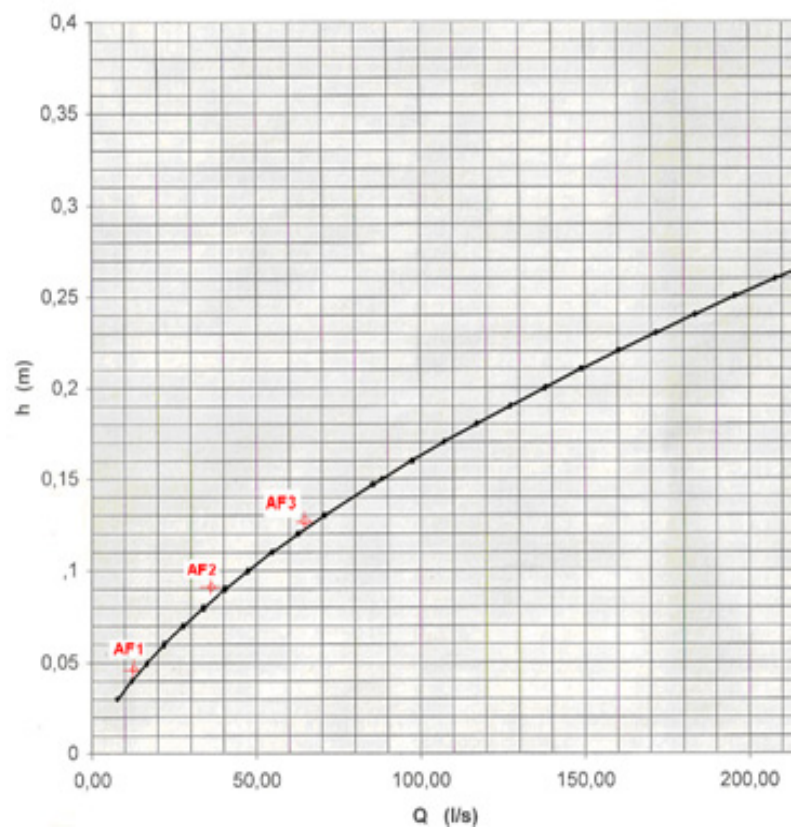

Figure 8: Curve elevations capabilities ISO-1438. 


\section{Conclusions}

In this paper we implement the hardware and software of a system of remote data acquisition, and the measurements of flow in open channels. The work presented is a system composed of several stages integrating flow measurement, a signal transmission meter, reception, and processing the suitability of all the information. This system can be periodically applied to monitor the expenditure of a canal or river and to obtain more accurate measurements. The next stage of this system is to adapt an electromechanical system, intelligent through servomechanisms and controlled by a PIC to make decisions on the depth and location of horizontal displacement sections.

\section{References}

[1] Howard M. B., The 55 timer applications sourcebook, with experiments, Indiana, pp. 69, 1980.

[2] SARH., Instructivo para aforos de corrientes, pp. 98, Mexico, 1957.

[3] IMTA, Instructivo para aforos con molinete, Mexico, pp. 16, 18, 28, [April 1997].

[4] Herrera P. J.C., Instructivo para aforos con molinete, Mexico, pp. 9-49, 1999.

[5] Martínez N. J., Sistema de adquisición de datos para medición de flujo en canal abierto, Mexico, pp. 10-15, 2010.

[6] ISO1438, Hidrometry - Open Channel flow measurement using thin-plate weirs. 